\title{
ECONOMIC GROWTH, URBANISATION AND CARBON EMISSIONS: EVIDENCE FROM SELECTED ASEAN COUNTRIES
}

\author{
Seng-Huat Tan ${ }^{1 *}$, Meenchee Hong ${ }^{2}$, Tze-Haw Chan² \\ ${ }^{1}$ Faculty of Business, Multimedia University, Melaka, Malaysia; Graduate School of Business Universiti Sains Malaysia, Malaysia \\ ${ }^{2}$ Graduate School of Business, Universiti Sains Malaysia, Penang, Malaysia
}

ABSTRACT - Climate change is considered as the most severe and urgent environmental issue in this present era. There is a clear consensus that climate change problem is much related to the rising level of carbon emissions in the atmosphere. The link between economic growth, urbanization and carbon emissions was examined extensively in the literature. Fast- aced economic growth will advance urbanization in a country and result in a higher energy consumption as to meet various needs in an urban economy. This conditions will trigger more carbon emissions and generate more pollution problem. This paper aims to discuss and compare the growth pattern of economic growth, urbanization and carbon emissions between five selected ASEAN countries such as Indonesia, Malaysia, Philippines, Thailand and Vietnam for the period 1990-2018. All these five countries have recorded at least $4 \%$ economic growth rate in the year 2018. In the same period, Indonesia has the largest in term of total value added in manufacturing. Similarly, Vietnam has the largest growth of value added in the same industry. Among all, Indonesia has the largest urban population whilst Malaysia has the highest rate in urbanization and carbon emissions per capita. The upward trend of urban population and carbon emissions per capita in these countries exhibit certain pressures and challenges to the countries' environmental quality. Therefore, government in these countries should pay attention to environmental governance to achieve sustainable urbanization while prioritizing economic growth.
ARTICLE HISTORY

Received: 15-4-2020

Accepted: 3-6-2020

KEYWORDS

Economic Growth

Urbanization

Carbon Emissions

\section{INTRODUCTION}

Climate change is one of the alarming environmental threats faced by the world in this era, and carbon emissions are considered as one of the main causes of the problem globally. The problem gained rising concerns as various countries have focused their efforts on reducing greenhouse gas (GHG) emissions to combat climate change (Francey et al., 2013). Meanwhile, urbanization has been recognized as a major cause of carbon emission and has contributed to increased environmental pollution (Tian et al., 2017; Hao et al, 2020). According to the United Nations (2018), at present, there is $55 \%$ of the world's population resides in urban areas and by 2050 , the figure is forecasted to rise to $68 \%$. Asia and Africa's regions are mainly contributing to this estimated increase. In 2018, Northern America has become the most urbanized region with $82 \%$ of its population living in urban areas, followed by Latin America and the Caribbean, Europe, and Oceania with an urbanization rate of $81 \%, 74 \%$, and $68 \%$ respectively. In addition, for the Asia region, the urbanization level is notably approaching $50 \%$ and in comparison, the Africa region remains rural with a $43 \%$ urban population.

Rapid population growth has a very close tie with urbanization. It generates energy consumption due to the construction works such as infrastructure and residential buildings. Besides that, the rise of various industries due to industrial development further stimulates the demand for energy in a country to support economic growth. Industrial development has a direct effect on society. It does not only offer jobs opportunities to many people but also improve their socio-economic status. However, with rapid economic growth coupling along with continuous growing urbanization, energy use will accelerate the volume of $\mathrm{CO}_{2}$ emissions globally. The adverse effects of $\mathrm{CO}_{2}$ on the economy and the environment come in various aspects and are obvious. According to NASA (2016), in the period between the years 1990 and $2013, \mathrm{CO}_{2}$ alone accounted for nearly $80 \%$ for each increase of $34 \%$ of total $\mathrm{GHG}$ in the atmosphere. In $2018, \mathrm{CO}_{2}$ emissions attributed to global energy grew by $1.7 \%$ (IEA, 2019). Hence, the proper mitigation policy actions must come in place, as such increasing trend of emissions seemed will continue at greater size and intensity in the future. This will potentially bring more damages to our environment.

ASEAN has been one of the regions that exhibit remarkable economic growth in the recent decade. Between the years 2000 to 2013, ASEAN recorded an economic growth rate with an annual average above 5\%, as compared to the OECD average growth rate, which was only 1.6\% (IEA, World Energy Outlook Special Report, 2015; Southeast Asia Energy Outlook, 2015). The energy demand for the ASEAN region will grow higher in the future, with an average growth rate of $4 \%$ annually compared to the world average of 1.8\% (IEA, World Energy Outlook, 2009). Hence, with the strong momentum of economic growth, it is expected that greater urbanization will occur in this region and lead to higher carbon emissions levels in the future due to increasing energy consumption. 
Despite the various research conducted on the relationships between economic growth, urbanization and carbon emissions for many years, the subject remains an important global policy debate with the presence of inconclusive findings and the need for a better understanding of the dynamic linkage of these variables. In conjunction with this situation, it is this research interest to study them in the ASEAN context.

\section{LITERATURE REVIEW}

Issues on environmental quality deterioration have always been gaining attention from past to present. Factors that responsible for environmental degradation are complex and dynamic. Many studies observed factor attribute for environmental degradation at local, regional, and global levels (Zhang et al., 2018a, 2018b; Zhang and Zhang, 2018).

The relationship between income, environment, and urbanization has been empirically examined with ample evidence in the literature. Given the continuous growth of the economy and population, the adverse effects of economic development on the environment have become important to human beings. In the 1970s, Ehrlich and Holdren (1971) first introduced the IPAT (I - Impact, P - Population, A - Affluence, and T - Technology) model to study the impact of human activities on environmental damage. However, this initial model and its reformulated version (for example, IPBAT by Schulze (2002) where human behavior decisions -B is included into the model and ImPACT by Waggoner and Ausubel (2002) where they decomposed the variable T into consumption per unit of GDP (C) and impact per unit of consumption (T)) were argued due to its too simplistic framework and a limited number of driving factors in testing the impacts on the environment. Dietz and Rosa (1997) modified the model into a stochastic version to overcome the problems. The modified model is known as STIRPAT (Stochastic Impacts by Regression on Population, Affluence, and Technology) and has been employed by many researchers to study the non-log linear relationship between the variables. According to York et al. (2003), the STIRPAT model allows more precise specification of driving factors that are responsible for environmental impacts and thus also reveals which specific factor being the most responsive to government environmental policy. In a recent study by Khoshnevis and Dariani (2019), the STIRPAT model was used to study the relationship between carbon emissions, urbanization, and economic growth based on the evidence in some selected Asian countries. Their findings supported that there is a long-run relationship between the variables and also revealed that urbanization drives energy consumption and causes carbon emissions.

A number of studies discussed that urbanization is a factor that influences the carbon dioxide emissions empirically for both developed and developing countries context (Al-mulali et al., 2013; Dogan and Turkekul, 2016). Sushinsky et al. (2013) opined that urbanization led to serious worldwide environmental degradation with growing size and intensity. Evidence from previous studies revealed that urbanization and environmental pollution conjointly influence each other (Chen et al., 2017; Han et al., 2018; Ali et al., 2019). According to Wang et al. (2020), factors such as population growth, urbanization, and industrialization play influential and fundamental role in increased demand for energy and therefore lead to increases in carbon emissions within a country.

Many studies concluded that urbanization and industrialization drive energy consumption in a country and therefore causing $\mathrm{CO}_{2}$ emissions (Zhou et al., 2013). Past studies examined how urbanization increases temperature (Chapman et al., 2017). For example, the evidence by Wiedenhofer et al. (2013) showed that urban residents produce more direct emissions compared to rural residents. Their consumption of goods and services is usually more than rural residents. Studies also found high consumption leads to indirect carbon emission to higher levels both domestically and globally (Feng et al., 2014; Tian et al., 2016). Therefore, the influence of urbanization on energy consumption demand global attention and commitment when dealing with climate change issues.

According to estimations by the International Energy Agency (IEA), urbanization is the source of about $70 \%$ of energy-related global carbon emissions and it is expected to increase to 76\% by 2030 (IEA, 2017). Many studies showed that urbanization and industrialization enhance the consumption of fossil fuel, which in turn emits carbon dioxide and other greenhouse gases (GHG) with a considerable quantity to the atmosphere (World Bank, 2007). The relationship between urbanization and $\mathrm{CO} 2$ emissions has been the focus of study for many years. As an example, some studies used co-integration models and Granger causality tests to examine the long-term and short-term relationships between CO2 emissions, energy consumption, and urbanization (Li and Lin, 2015; Ouyang and Lin, 2017; Wang et al., 2016a). The findings showed the presence of unilateral short-run causal relationships for urbanization and energy consumption. A similar result was also observed between urbanization and CO2 emissions. More importantly, in the long run, urbanization coupled with energy consumption will result in rising CO2 emissions (Wang et al., 2016b).

In the body of literature, a number of works investigated the relationships between $\mathrm{CO}_{2}$ emissions, economic growth, and urbanization across countries. However, the study on the relationship between $\mathrm{CO}_{2}$ emissions, economic growth, and urban population for ASEAN is rather limited. The conclusion from these past studies is still subject to further argument. Hence, this study aims to fill this gap in the literature by discussing the relationships of the variables of interest in the context of five selected ASEAN countries.

\section{METHODOLOGY}

This study illustrated the trends for economic growth, urbanization, industrialization, and carbon emissions for five selected ASEAN countries namely, Indonesia, Malaysia, Philippines, Thailand, and Vietnam. They represent five important economies after Singapore in the ASEAN region. The data for these countries were collected from the World Bank Data Indicator for the period of the year 1990 until 2018. The variable of economic growth was measured based on 
the annual growth rate, value-added of manufacturing was used as a proxy for industrialization, the urban population was used to indicate the urbanization level and the carbon emissions per capita was computed based on the urban population.

\section{FINDINGS AND DISCUSSION}

\section{Economic growth in ASEAN}

Table 1 shows economic growth for the selected ASEAN countries (Indonesia, Malaysia, Philippines, Thailand, and Vietnam) from the year 1990 to 2018. These countries represent top developing economies in the Southeast Asia region after Singapore with greater economic potentials. ASEAN has been recognized as one of the fast-growing regions in the world. Positioned with strong prospects of economic growth, it is expected that the urbanization rate in ASEAN will continue to rise. In 2018, all five countries have at least a $4 \%$ economic growth rate. Vietnam has the most remarkable growth compared to others with $7.08 \%$, followed by the Philippines (6.24\%), Indonesia (5.17\%), Malaysia, and Thailand (4.72\% and $4.13 \%$ respectively). This great momentum of economic growth will shape the scale of economic activities, urbanization, and further on the carbon emissions level in this region. Therefore, the issues surrounding these variables will arise and tend to become more challenging in the future.

Table 1: Economic growth, 1990 -2018

\begin{tabular}{lllll}
\hline \multirow{2}{*}{ Country } & \multicolumn{4}{l}{ Economic growth (annual percentage growth rate) } \\
\cline { 2 - 5 } & $\mathbf{1 9 9 0}$ & $\mathbf{2 0 0 0}$ & $\mathbf{2 0 1 0}$ & $\mathbf{2 0 1 8}$ \\
\hline Indonesia & 7.24 & 4.92 & 6.22 & 5.17 \\
Malaysia & 9.00 & 8.86 & 7.42 & 4.72 \\
Philippines & 3.04 & 4.41 & 7.63 & 6.24 \\
Thailand & 11.17 & 4.46 & 7.51 & 4.13 \\
Vietnam & 5.10 & 6.79 & 6.42 & 7.08 \\
\hline
\end{tabular}

Source: World Bank Data Indicator, 2019

\section{Increasing manufacturing activity in ASEAN}

The industrialization has always been a significant and important factor that promotes economic development in all countries. It also represents a major structural transformation for many countries on their economic growth path. As the country develops, the role of industrialization on environmental quality starts to emerge. The industrial sector plays an important role in the effort of reducing carbon emissions (Congregado et al., 2016; Muhammad and Lean, 2011). Table 2 shows the value-added of the manufacturing sector for ASEAN for the period of 1990-2018. Overall, the growth of total value added of the manufacturing sector has been at strong momentum in 30 years in which the value-added in 2018 has been at least threefold compared to those in 1990. In 2018, Indonesia has the highest value-added which is $\$ 241.3$ billion, followed by Thailand ( $\$ 121.1$ billion), Malaysia ( $\$ 87.9$ billion), Philippines ( $\$ 72.6$ billion and Vietnam ( $\$ 34.3$ billion). Interestingly, although Vietnam has the least in terms of value-added it has the largest growth of that with nearly thirteen-fold since 1990 among all five countries. Meanwhile, for the same period, the growth of value-added in manufacturing for the rest is Malaysia with 5.4, Indonesia (4.2), Thailand (3.8), and Philippines (3.2). The rising valueadded of manufacturing activity from these countries reveals that industrialization continues to contribute to ASEAN economic growth and strengthen the position of manufacturing as a share of GDP and thus prove the important developmental role of industrialization.

Table 2: Manufacturing, value-added, 1990 -2018

\begin{tabular}{lcccc}
\hline \multirow{2}{*}{ Country } & \multicolumn{4}{c}{ Manufacturing, valued-added (billion) } \\
\cline { 2 - 5 } & $\mathbf{1 9 9 0}$ & $\mathbf{2 0 0 0}$ & $\mathbf{2 0 1 0}$ & $\mathbf{2 0 1 8}$ \\
\hline Indonesia & 57037863777.3 & 107460259013.3 & 166412397525.6 & 241271931449.1 \\
Malaysia & 16242417248.8 & 41914911334.6 & 59760019868.9 & 87962807736.5 \\
Philippines & 22983111088.6 & 29654669658.7 & 42801858624.6 & 72604792479.83 \\
Thailand & 32132291822.6 & 62017244463.6 & 105987054097.0 & 121107183053.2 \\
Vietnam & 2768664861.7 & 77001587145.7 & 15008931942.4 & 34393964703.0 \\
\hline
\end{tabular}

Source: World Bank Data Indicator, 2019

\section{Increasing urban population in ASEAN}

According to Sadorsky (2014), urbanization in developing countries continues to grow apart from developed countries. By 2050, the developing countries will account for almost $65 \%$ of urbanization that will occur (Shahbaz, et al. 2016). The continents of Asia and Africa will see the highest rate of urbanization as it will be double from the year 2000 to 2030. Urbanization is considered important as part of the economic growth path (Seto et al., 2010; Glaeser, 2011). A similar pattern is also present for ASEAN regions in which the urban population continues to increase (see Table 3 ) due to the growing economy. All five countries experienced an increase in urban population between the period of 1990 and 2018. In 2018, more than half of the population in Malaysia and Indonesia resided in urban areas with Malaysia has the highest urbanization rate which is $76.04 \%$, followed by Indonesia (55.32\%), Thailand (49.95\%), Philippines (46.91\%), and Vietnam $(35.92 \%)$. The increased urbanization will not only benefit the local economy but will also pose some 
problems to the economy at the same time. Among them are developmental pressures on housing, transportation, land usage, waste and pollution, health, etc.

Table 3: Urban population rate, 1990- 2018

\begin{tabular}{ccccc}
\hline \multirow{2}{*}{ Country } & \multicolumn{4}{c}{ Urban population (\% of total population) } \\
\cline { 2 - 5 } & $\mathbf{1 9 9 0}$ & $\mathbf{2 0 0 0}$ & $\mathbf{2 0 1 0}$ & $\mathbf{2 0 1 8}$ \\
\hline Indonesia & 30.58 & 42.00 & 49.91 & 55.32 \\
Malaysia & 49.79 & 61.97 & 70.91 & 76.04 \\
Philippines & 46.99 & 46.14 & 45.33 & 46.91 \\
Thailand & 29.42 & 31.39 & 43.86 & 49.95 \\
Vietnam & 19.50 & 24.37 & 30.41 & 35.92 \\
\hline
\end{tabular}

\section{Rising carbon emissions per capita in ASEAN}

As a major source of GHG emissions, the threats of global warming and climate change caused by carbon emissions are notable. The rising carbon emissions level will harm the environment. Figure 1 and Figure 2(a) -2(e) present the trend of growth for urban population and carbon emissions per capita for five selected ASEAN countries. Overall, all five countries experienced an increase in their urban population between the year 1990 to 2014, where Indonesia has the largest size of urban population and Malaysia has the least. In contrast, Malaysia has the highest level of carbon emissions per capita compared to the rest of the countries for the same period. The concern on the environmental issue will remain high to the ASEAN government in the upcoming years as all five countries exhibited a rising level of carbon emissions per capita due to urban population growth. This is particularly relevant to carbon emissions mitigation strategy in line with the emphasis on sustainable development.

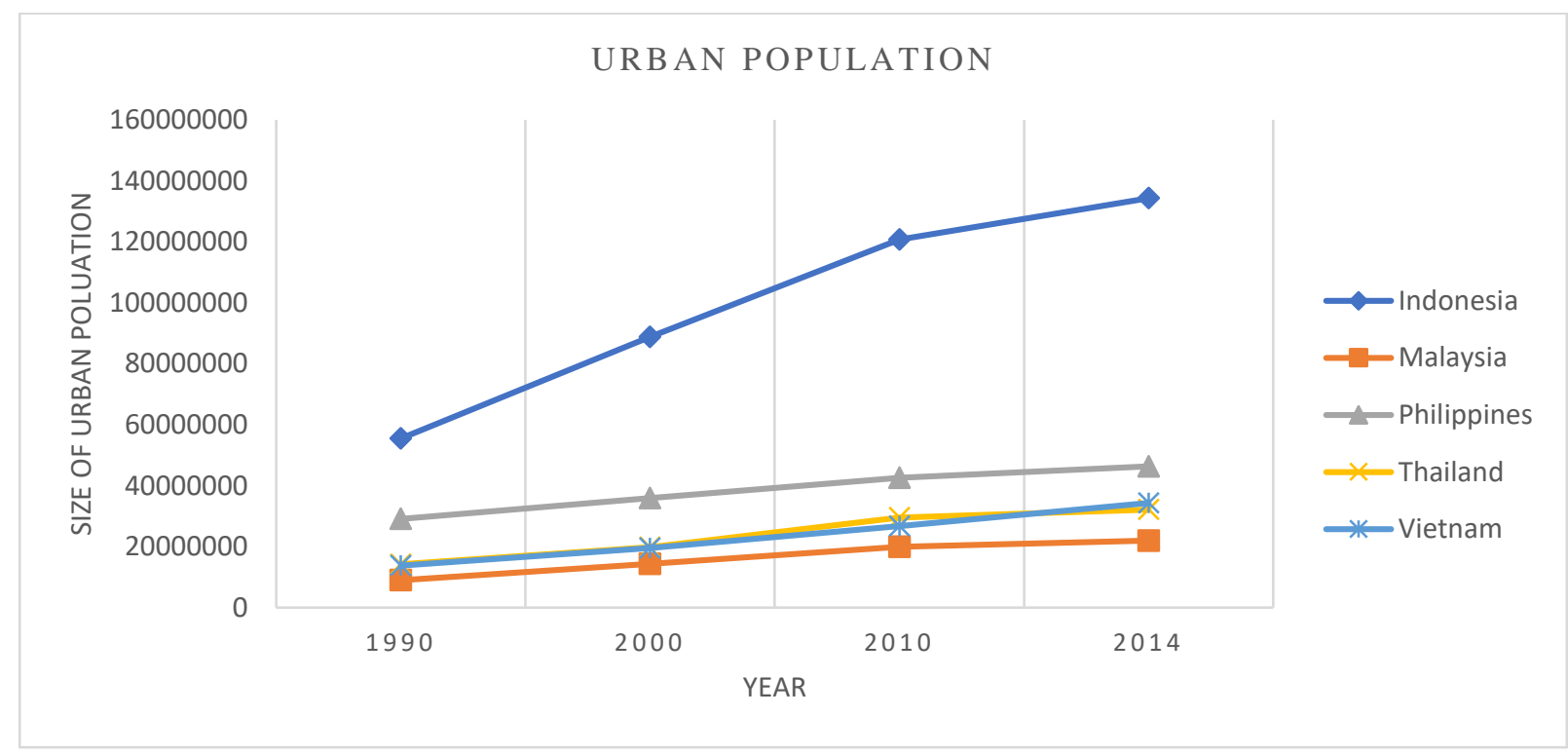

Figure 1. Urban population, 1990 -2014

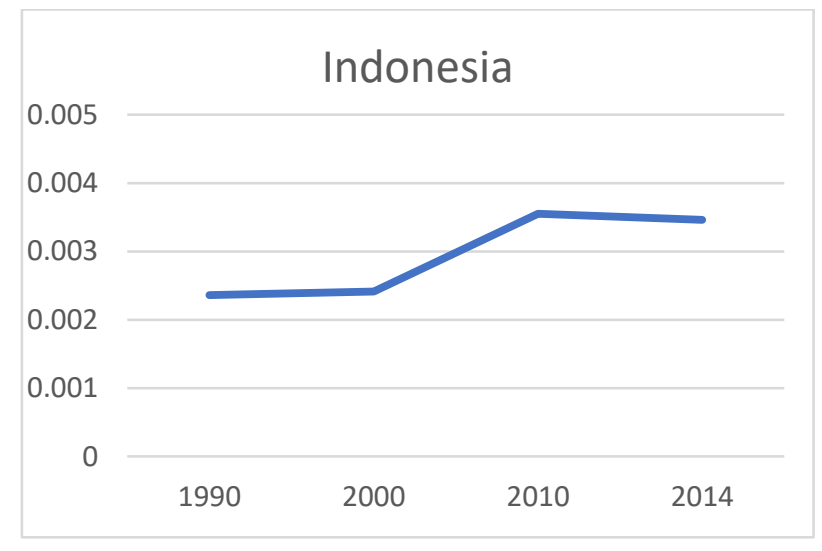

Figure 2(a) 


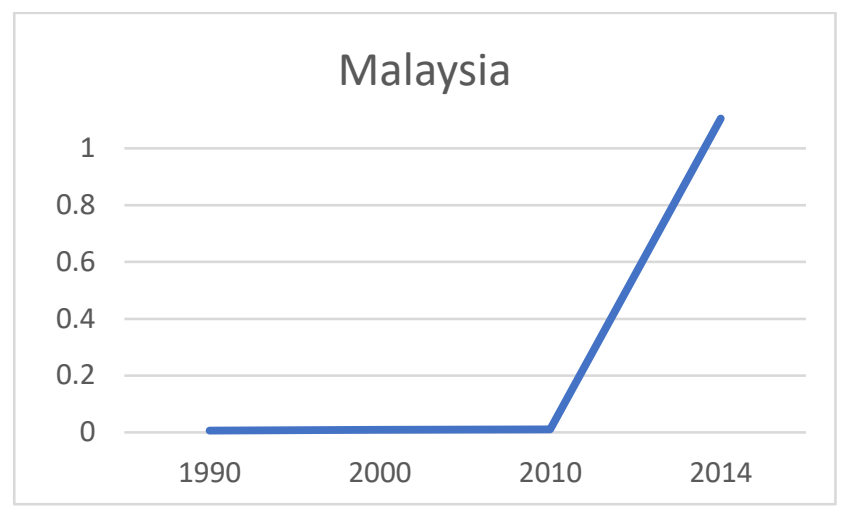

Figure 2(b)

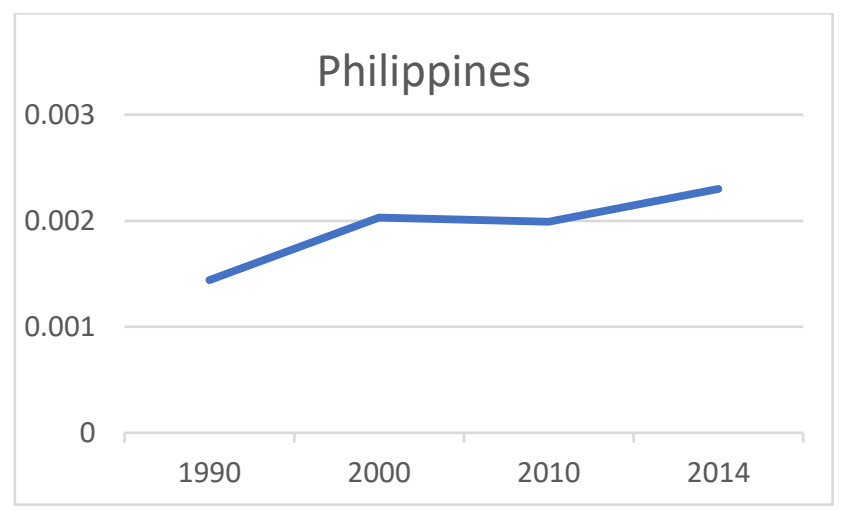

Figure 2(c)

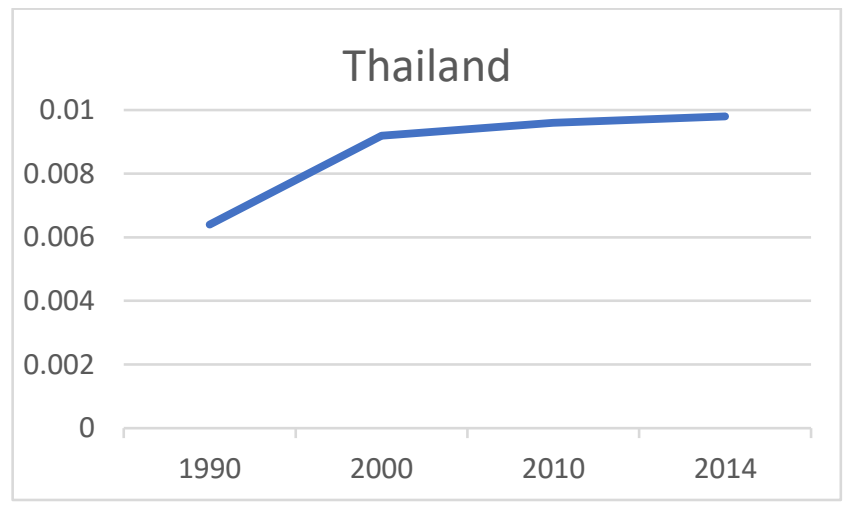

Figure 2(d)

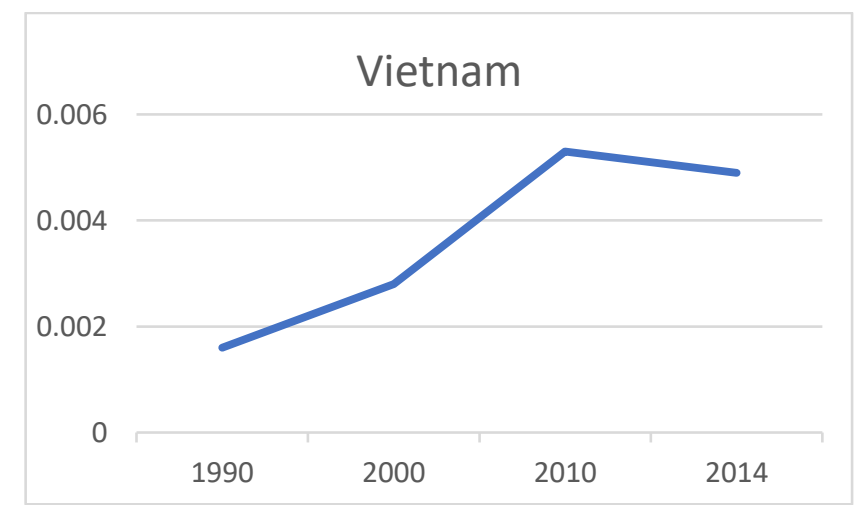

Figure 2(e)

Figure 2(a) - 2(e). Carbon emissions per capita, 1990 -2014

Note: The carbon emissions per capita is measured based on urban population. 


\section{CONCLUSION}

Economic growth is an important development goal in both developed and developing countries. In the context of developing countries, economic growth is a portrayal of the thoughts of the government to eradicate poverty and to gain a better standard of living among people nationwide. This includes ASEAN countries as well. Urbanization is an inevitable phenomenon that is tied to economic development. It is a global trend that indicates the growing population in the world. It is expected that in the Asian region, urbanization will continue to increase (Khoshnevis and Dariani, 2019). Two main factors underlying urbanization include the natural increase of population and rural migrants to the urban area. These two causes will continue to contribute to urbanization following continuous economic growth around the world. In the long run, the effect of urbanization on the environment will necessarily remain as policymakers' top agenda due to the concern on sustainable development, particularly on environmental sustainability.

All five ASEAN countries in this study have exhibited encouraging economic growth rates for the period 1990 to 2018. At the same time, these economies also have witnessed remarkable growth in their manufacturing value-added. Economic growth and urbanization have a mutually beneficial relationship. Along with the effect of economic growth, it also shows that urbanization has increased for these countries over 30 years. Moreover, these countries experienced a continuous growing urban population in which lead to more carbon emissions occurred in the atmosphere within the countries. It is observed that urbanization has a positive effect on economic growth. However, policymakers should pay attention as rapid urbanization may negatively influence economic growth. Rapid urbanization is accompanied by an increase in energy demand and may lead to many serious environmental problems (Wang et al., 2020). Therefore, it is an important challenge for policymakers to maintain a balance between urbanization and sustainable development (Wang et al, 2014). Policymakers need to pay attention to matters of environmental governance to achieve a healthy level and quality of urbanization.

\section{REFERENCES}

Ali, R., Bakhsh, K., \& Yasin, M. A. (2019). Impact of urbanization on CO2 emissions in emerging economy: evidence from Pakistan. Sustainable Cities and Society, 48, 101553.

Al-mulali, U., Fereidouni, H. G., Lee, J. Y., \& Sab, C. N. B. C. (2013). Exploring the relationship between urbanization, energy consumption, and CO2 emission in MENA countries. Renewable and Sustainable Energy Reviews, 23, 107-112.

Chapman, S., Watson, J. E., Salazar, A., Thatcher, M., \& McAlpine, C. A. (2017). The impact of urbanization and climate change on urban temperatures: a systematic review. Landscape ecology, 32(10), 1921-1935.

Chen, S., Oliva, P., \& Zhang, P. (2017). The effect of air pollution on migration: evidence from China (No. w24036). National Bureau of Economic Research.

Congregado, E., Feria-Gallardo, J., Golpe, A. A., \& Iglesias, J. (2016). The environmental Kuznets curve and CO 2 emissions in the USA. Environmental Science and Pollution Research, 23(18), 18407-18420.

Dietz, T., \& Rosa, E. A. (1997). Effects of population and affluence on CO2 emissions. Proceedings of the National Academy of Sciences, 94(1), 175-179.

Dogan, E., \& Turkekul, B. (2016). CO 2 emissions, real output, energy consumption, trade, urbanization and financial development: testing the EKC hypothesis for the USA. Environmental Science and Pollution Research, 23(2), 1203-1213.

Ehrlich, P. R., \& Holdren, J. P. (1971). Impact of population growth. Science, 171(3977), 1212-1217.

Feng, K., Hubacek, K., Sun, L., \& Liu, Z. (2014). Consumption-based CO2 accounting of China's megacities: the case of Beijing, Tianjin, Shanghai and Chongqing. Ecological Indicators, 47, 26-31.

Francey, R. J., Trudinger, C. M., Van Der Schoot, M., Law, R. M., Krummel, P. B., Langenfelds, R. L., \& Rödenbeck, C. (2013). Atmospheric verification of anthropogenic CO 2 emission trends. Nature Climate Change, 3(5), 520-524.

Glaeser, E. (2011). Cities, productivity, and quality of life. Science, 333(6042), 592-594.

Han, L., Zhou, W., Li, W., \& Qian, Y. (2018). Urbanization strategy and environmental changes: an insight with relationship between population change and fine particulate pollution. Science of the total environment, 642, 789-799.

Hao, Y., Zheng, S., Zhao, M., Wu, H., Guo, Y., \& Li, Y. (2020). Reexamining the relationships among urbanization, industrial structure, and environmental pollution in China-New evidence using the dynamic threshold panel model. Energy Reports, 6 , 28-39.

IEA, 2009. World Energy Outlook 2009. IEA, Paris. Retrieved from https://www.iea.org/reports/world-energy-outlook-2009.

IEA, 2015, World Energy Outlook Special Report, 2015. Retrieved from https://www.iea.org/reports/energy-and-climate-change

IEA, 2015, Southeast Asia Energy Outlook, 2015.IEA, Paris. Retrieved from https://www.iea.org/reports/southeast-asia-energyoutlook-2015

IEA , 2017. CO 2 emissions from fuel combustion 2017 - Highlights. Int. Energy Agency 1, 1-162. Retrieved from https://doi: 10.1787/co2 _ fuel-2017-en .

IEA, 2019. Global Energy and CO2 Status Report 2019, Retrieved from https://www.iea.org/reports/global-energy-co2-status-report2019

Khoshnevis Yazdi, S., \& Dariani, A. G. (2019). CO2 emissions, urbanisation and economic growth: evidence from Asian countries. Economic research-Ekonomska istraživanja, 32(1), 510-530.

Li, K., \& Lin, B. (2015). Impacts of urbanization and industrialization on energy consumption/CO2 emissions: does the level of development matter?. Renewable and Sustainable Energy Reviews, 52, 1107-1122. 
Muhammad, S., \& Lean, H. H. (2011). Does financial development increase energy consumption? role of industrialization and urbanization in Tunisia.

Nasa, The Cost of Energy and Environmental Impact, The National Academies of Sciences, Engineering and Medicine, 2016. Retrieved from https:// needtoknow.nas.edu/energy/energy-costs/environmental/.

Ouyang, X., \& Lin, B. (2017). Carbon dioxide (CO2) emissions during urbanization: a comparative study between China and Japan. Journal of Cleaner Production, 143, 356-368.

Sadorsky, P. (2014). The effect of urbanization on CO2 emissions in emerging economies. Energy Economics, 41, 147-153.

Seto, K. C., Sánchez-Rodríguez, R., \& Fragkias, M. (2010). The new geography of contemporary urbanization and the environment. Annual review of environment and resources, 35, 167-194.

Schulze, P. C. (2002). I= PBAT. Ecological economics, 40(2), 149-150.

Shahbaz, M., Loganathan, N., Muzaffar, A. T., Ahmed, K., \& Jabran, M. A. (2016). How urbanization affects CO2 emissions in Malaysia? The application of STIRPAT model. Renewable and Sustainable Energy Reviews, 57, 83-93.

Sushinsky, J. R., Rhodes, J. R., Possingham, H. P., Gill, T. K., \& Fuller, R. A. (2013). How should we grow cities to minimize their biodiversity impacts?. Global change biology, 19(2), 401-410.

Tian, X., Chang, M., Shi, F., \& Tanikawa, H. (2017). Decoding the effect of socioeconomic transitions on carbon dioxide emissions: Analysis framework and application in megacity Chongqing from inland China. Journal of Cleaner Production, 142, $2114-2124$.

Tian, X., Geng, Y., Dai, H., Fujita, T., Wu, R., Liu, Z., ... \& Yang, X. (2016). The effects of household consumption pattern on regional development: a case study of Shanghai. Energy, 103, 49-60.

UN 2018 United Nation, Retrieved from https://www.un.org/development/desa/en/news/population/2018-revision-of-worldurbanization-prospects.html

Wang, S., Fang, C., Guan, X., Pang, B., \& Ma, H. (2014). Urbanisation, energy consumption, and carbon dioxide emissions in China: A panel data analysis of China's provinces. Applied Energy, 136, 738-749.

Wang, S., Gao, S., Li, S., \& Feng, K. (2020). Strategizing the relation between urbanization and air pollution: Empirical evidence from global countries. Journal of Cleaner Production, 243, 118615.

Wang, S., Li, Q., Fang, C., \& Zhou, C. (2016a). The relationship between economic growth, energy consumption, and CO2 emissions: Empirical evidence from China. Science of the Total Environment, 542, 360-371.

Wang, Y., Chen, L., \& Kubota, J. (2016b). The relationship between urbanization, energy use and carbon emissions: evidence from a panel of Association of Southeast Asian Nations (ASEAN) countries. Journal of Cleaner Production, 112, 1368-1374.

Waggoner, P. E., \& Ausubel, J. H. (2002). A framework for sustainability science: A renovated IPAT identity. Proceedings of the National Academy of Sciences, 99(12), 7860-7865.

Wiedenhofer, D., Lenzen, M., \& Steinberger, J. K. (2013). Energy requirements of consumption: Urban form, climatic and socioeconomic factors, rebounds and their policy implications. Energy policy, 63, 696-707.

World Bank, 2007. World Development Report 2007. Development and the Next Generation. Retrieved from https//:doi/org/10. 1596/978- 0- 8213- 6541- 0 .

World Bank Data Indicator, 2019. Retrieved from https://data.worldbank.org/indicator

York, R., Rosa, E. A., \& Dietz, T. (2003). STIRPAT, IPAT and ImPACT: analytic tools for unpacking the driving forces of environmental impacts. Ecological economics, 46(3), 351-365.

Zhang, Y. J., \& Zhang, K. B. (2018). The linkage of CO 2 emissions for China, EU, and USA: evidence from the regional and sectoral analyses. Environmental Science and Pollution Research, 25(20), 20179-20192.

Zhang, Y. J., Bian, X. J., \& Tan, W. (2018a). The linkages of sectoral carbon dioxide emission caused by household consumption in China: evidence from the hypothetical extraction method. Empirical Economics, 54(4), 1743-1775.

Zhang, Y. J., Jin, Y. L., \& Shen, B. (2018b). Measuring the energy saving and CO 2 emissions reduction potential under China's belt and road initiative. Computational Economics, 1-22.

Zhou, X., Zhang, J., \& Li, J. (2013). Industrial structural transformation and carbon dioxide emissions in China. Energy policy, 57, 4351. 


\section{AUTHORS' BIOGRAPHY}

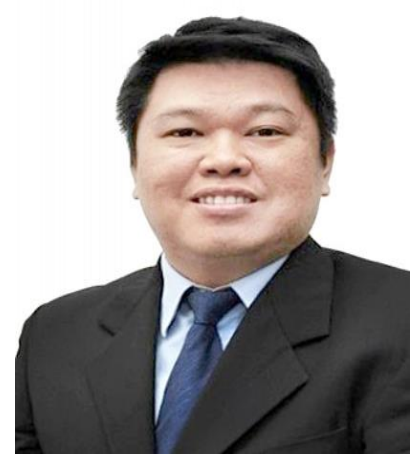

Seng Huat Tan is a lecturer at Faculty of Business, Multimedia University. He currently pursue his doctorate study at the Graduate School of Business, Universiti Sains Malaysia.

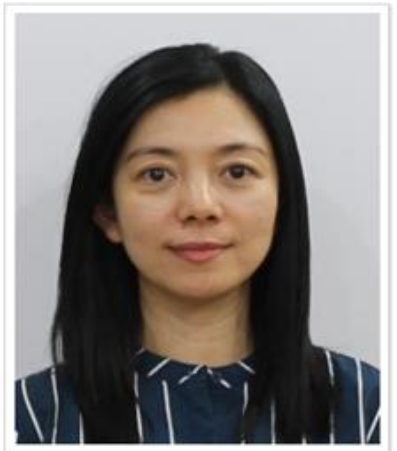

Meenchee Hong is a senior lecturer at the Graduate School of Business, Universiti Sains Malaysia. She obtained her PhD (Economics) at James Cook University, Australia. Besides teaching, she is also active in research, particularly in the area of industry economics, circular economy and sustainability related issues.

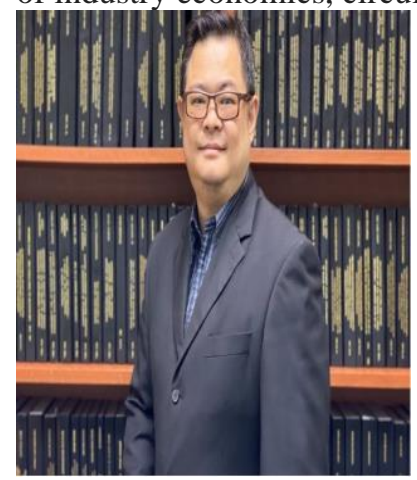

Dr Chan Tze-Haw is a senior lecturer at Graduate School of Business, Universiti Sains Malaysia. He was the founder of the Centre for Globalization and Sustainability Research (CGSR), Multimedia University. Dr Chan actively involved with research and consultation projects related to Industry Competitiveness, Financial Economics and Applied Econometrics, and has been listed as Top-22\% economists in Asia by the RePEc database. 